\title{
Reverberações
}

\section{das cartas de}

\author{
alforria nas
}

\section{discriminações}

\author{
étnicas.
}

\section{Júlio César dos Santos \\ Universidade Federal do Recôncavo da \\ Bahia (UFRB) \\ economiapsicologia@gmail.com}

Aline Souza da Conceição

Universidade Federal do Recôncavo da

Bahia (UFRB)

alinesdc02@gmail.com

DOI: https://doi.org/10.22481/odeere.v0i4.2371

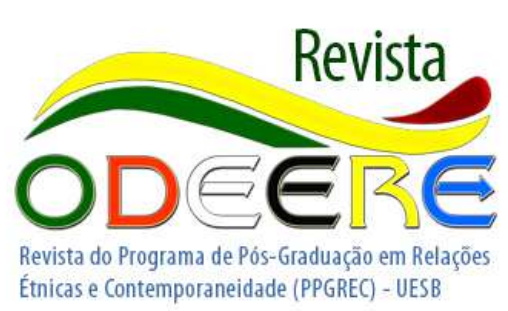

Resumo: O objetivo do artigo é entender as narrativas nas cartas de alforria, como dinâmicas de produção de sentidos intergeracionais de pessoas em situações de discriminações étnicas. Questionamos os temas nas cartas de alforria que marcam narrativas de discriminação étnica nas ações e atividades atuais. O método de pesquisa foi uma busca documental nos cartórios da cidade por cartas de alforria e inventários de família com declarações de posse de uma pessoa sobre a outra, de 1872 a 1888 . Um outro método se constitui na escolha de 3 homens da mesma família no corte do corpus de narrativas de doze homens, de três gerações, da cidade de Santo Antônio de Jesus, Bahia. Foram realizadas quarenta e oito horas de gravações de áudio e vídeo em entrevistas de história de vida e episódica. $\mathrm{Na}$ análise de conteúdo temática da narrativa das cartas de alforria foram encontradas reverberações dos mesmos temas de discriminação, racismo e preconceito étnico nas narrativas dos participantes. Foi escolhida a narrativa de P32 por apresentar vários significados que discriminam as populações negras no interior da comunidade do Quilombo Alto do Morro, como o "trabalho doméstico"; "a minha cor assim". O foco da narrativa enfatiza o impacto da educação, como prática cultural em detrimento aos processos discriminatórios aos "de minha cor assim". Conclui-se que a quantidade de leis contra o racismo sinaliza questões intergeracionais importantes, em como a reverberações dos significados, a dinâmica de produção de sentidos intergeracional de negros alforriados paralisa algumas pessoas, seus 
ancestrais e descendentes. Ao mesmo tempo constituíram-se significados de negações, de esquecimentos dos episódios de pessoas de uma mesma família do tratamento como inferior, com todos os processos cognitivos possíveis.

Palavras-Chave: intergeracionalidade, relaçõesvétnicas, produção de sentidos, populações negras.

Abstract: The purpose of the article is to understand the narratives in the letters of manumission, as dynamics of production of intergenerational senses of people in situations of ethnic discrimination. We question the themes in the letters of manumission that mark narratives of ethnic discrimination in the current actions and activities. The search method was a documentary search in the city notaries for letters of manumission and family inventories with declarations of possession of one person over the other, from 1872 to 1888. Another method is the choice of 3 men from the same family in the cut of the corpus of narratives of twelve men, three generations, from the city of Santo Antônio de Jesus, Bahia. Forty-eight hours of audio and video recordings of the life history and episodic interviews were exacerbated. In the analysis of the thematic content of the narrative of the manumission letters were found reverberations of the same themes of discrimination, racism and ethnic prejudice in the narratives of the participants. The narrative of P32 was chosen because it presents several meanings that discriminate against the blacks inside the Quilombo Alto do Morro community, as "domestic work"; "My color like that". The focus of the narrative emphasizes the impact of education as a cultural practice over discriminatory processes to those of "my color". It is concluded that the number of laws against racism signals important intergenerational issues, as in the reverberations of meanings, the intergenerational sense production dynamics of freed blacks paralyzes some people, their ancestors and descendants. At the same time they constitute meanings of denials, of forgetting the episodes of people from the same treatment family as inferior, with all possible cognitive processes.

Keywords: intergenerationality, ethnic relations, production of meanings, black populations.

\section{Introdução ${ }^{1}$}

O objetivo do artigo é entender as narrativas nas cartas de alforria, como dinâmicas de produção de sentidos intergeracionais de pessoas em situações de discriminações étnicas. Utilizou-se as cartas de alforria como objeto impresso de significados, mais conhecidos como artefato mediacionais de comunicação entre as pessoas na família que constituíram formas de dinâmicas de produção de sentidos. O foco é identificar as marcas das maneiras como a população negra se posicionava, como também eram posicionados, às experiências atuais de narrativas de discriminações raciais.

A narrativa como método diz respeito às características que nos permitem uma análise Pragmática Linguística minuciosa das reverberações dos temas até entrar na psicologia: entre o

\footnotetext{
${ }^{1}$ Fomento CNPq - Bolsas PIBIC Ensino Médio.
} 
texto, contexto e intertexto; o intersubjetivo no subjetivo; os processos de significação; a construção de significados, a dinâmica de produção de sentidos; os posicionamentos do self. 0 método narrativo está na direção de uma psicologia narrativa, popular e discursiva que se fundamenta no processo de significação. Observar as reverberações dos temas de forma minuciosa nos permite entender as mudanças de significados, ressignificações, micro revoluções nas histórias de vida, em que com métodos mais tradicionais se observa apenas linearidade ${ }^{2}$.

Um dos exemplos, de micro revolução foi o conflito jurídico empreendido pelos pesquisadores para a liberação das cartas de alforria na cidade de Santo Antônio de Jesus. O conflito jurídico se constitui em evento idiossincrático que nos possibilitou as mudanças de sentidos, em que foi possível entender a importância social das cartas de alforria, como as intersubjetividades. Para entender o ser humano na intersubjetividade, é preciso entender que a comunicação possibilita a convivência entre os humanos. Na subjetividade da importância das cartas a partir das narrativas para solução do conflito jurídico identifica no discurso entre o cartório e o pesquisador o empoderamento de famílias negras, pois desencadeiam operações disjuntivas, produtoras de acontecimentos diferenciados, incoerências, jogos específicos de cada comunidade entre táticas de ações pessoais e atividades convencionais em comunidade ${ }^{3}$. As pessoas se apropriam dos significados culturais com estratégias pessoais, subjetivas, constituindo por vezes, micro-resistências às operações das atividades no tecido social. A cultura forma um tecido de significados que as comunidades acumulam, atualizam e transmitem sobre o qual se estrutura o mecanismo das interações cotidianas ${ }^{4}$. A cultura está nas explicações sobre a formação da mente como parte do funcionamento humano, o qual constitui ferramentas para vencer o desafio do desenvolvimento ${ }^{5}$.

Neste sentido os membros das famílias são capazes de criar novas soluções para situaçõesproblema, como também de consolidar e transmiti-las para a próxima geração através da circulação de significados com apropriação cultural, mediadas por narrativas das explicações

\footnotetext{
${ }^{2}$ Certeau, Michel de. A invenção do cotidiano: as artes do fazer. Petrópolis: Vozes, 1998.

${ }^{3}$ Marques, Welisson. Funcionalismo, pragmática e análise do discurso: reflexões analítico-críticas. Revista Odisséia. Volume 3, número 0, 2009, (1-19), Disponível em http://www.periodicos.ufrn.br/odisseia/article/view/2055/1489 consultado em 15 de setembro de 2017.

4 Velho, Ana Paula Machado. A semiótica da cultura: apontamentos para uma metodologia de análise da comunicação. Revista Estudos Comunicativos, volume 10, número 23, 2009, (249-257),. Disponível em http://www2.pucpr.br/; consultado em 15 de setembro de 2017.

${ }^{5}$ Bruner, Jerome Seymour. A. Actos de significado: Más allá de la revolución cognitiva. Madrid: Alianza Editorial, 1991.
} 
históricas sobre as interações dialéticas entre as gerações e pessoas ${ }^{6},{ }^{7}$. Os significados de ideias e gostos dos avós podem ser construídos nos netos, nos filhos e se concretizar nas narrativas mais em um do que em outro, pela convivência direta ou indireta, por exemplo; mas nas teorias dialógicas considera-se a responsividade de cada interlocutor enfatizando-se a dialética entre mudanças e permanência entre as gerações em movimentos dialógicos dinamogênicos. Quando histórias são contadas na família, comentários são feitos, etc. O mesmo ocorre com ideologias econômicas e práticas culturais de uma geração de famílias que são construídas em outras ${ }^{8}$.

Sendo assim, mudanças podem ocorrer a partir de diferentes dinâmicas por reinterpretação ativa dos interlocutores que direcionamos os estudos sobre a produção de sentidos intergeracional à análise das narrativas, cartas de alforria como parte da memória coletiva $^{9}$, considerando articulada a memória individual ${ }^{10}$.

Os movimentos conversacionais a respeito da alforria se localizam nas sequências polifônicas que afetam seu conteúdo semântico, bem como, pragmático. Assim nas pesquisas de cartas de alforria de pessoas em famílias de ascendentes alforriados deve-se combinar uma análise a nível local com outras análises ${ }^{11}$. É possível encontrar as estratégias cognitivas, do conhecer mediadas por cartas de alforria entre silêncios e enunciados. Supomos, assim, que se identificam as formas do discurso junto com os movimentos do discurso dos alforriados.

As cartas de alforria, como artefatos mediacionais podem apontar para diferenças de alforria, a resiliência do escravizado e a criação de oportunidades para sua resistência, os processos de discriminações nas interações na geração e entre geração, as revoltas em larga escala entre o século XVII até a primeira metade do século XIX ${ }^{12}$. A carta sugere uma interpretação

\footnotetext{
${ }^{6}$ Bakhurst, David. Il'enkov On Education. Studies in East European Thought: The Philosophy of Evald Il'enkov volume 57, número (3/4), (261-275), 2005. Disponível em www.jstor.org. Acessado em 15 de setembro de 2017.

${ }^{7}$ Fracchia, Joseph, \& Lewontin, Richard Charles. Forum: does culture evolve? The price of metaphor. History and Theory. Volume 44, (14-29), 2005. Disponível em www.periodicos.capes.gov.br, consultado em 15 de setembro de 2017.

8 Idem.

${ }^{9}$ Halbwachs, Maurice. A memória coletiva. 1ạ Ed, São Paulo: Editora Centauro, 2006.

${ }^{10}$ Fracchia, Joseph. Hora: Social Conflicts and Collective Memories in Piana Degli Albanesi. Past and Present, volume 209, número 1, (181-222), 2010. Disponível em www.periodicos.capes.gov.br. Consultado em 15 de setembro de 2017.

${ }^{11}$ Santos, Julio César. A produção de sentidos intergeracional de homens sobre o planejamento familiar. (Tese) doutorado. Universidade de Brasília - DF, Instituto de Psicologia, Programa de Pós-Graduação em Processos de Desenvolvimento Humano, 2015.

${ }^{12}$ Bernardino-Costa, Joaze e Grosfoguel, Ramón. Decolonialidade e perspectiva negra. Soc. estado. [online]. volume 31, número 1, (15-24), 2016. In: http://dx.doi.org/10.1590/S0102-69922016000100002. Consultado em 15 de setembro 2017.
} 
para o sentido sistêmico do escravismo brasileiro sem dissociar a condição escrava da condição liberta, o tráfico das manumissões, o tráfico de alforriados.

Nos posicionamentos a respeito das narrativas de discriminações encontram-se desafios de pessoas em famílias afrodescendentes em interações com não-afrodescendentes, que são desencadeados pela importância do enunciado nas negociações dos conflitos que se insere as questões intergeracionais nas relações etnicas. Vivenciamos situações complexas de conflito entre etnias no contexto socioeconômico com narrativas de preconceitos de inferioridade a respeito do outro, o enunciar a respeito do outro sem entender os significados que ora estão em construção.

Os preconceitos indicam o conflito na geração e entre gerações em se posicionarem entre diferentes culturas étnicas, discriminações em situações de chistes, gozações, piadas, risos nas narrativas atuais. Os posicionamentos em contextos de práticas culturais discriminatórias, formam os processos de socialização com traumas, sentimentos de inferioridade que constituem possíveis entraves para a auto declaração de pertencimento à uma comunidade negra. Pouco se encontra de narrativas do próprio sujeito de negro no seu processo de funcionamento humano a respeito das interações com as cartas de alforria, seus silêncios e regras; da interação deste sujeito com pessoas de sua comunidade, como também com o resto da sociedade. Nosso argumento da ausência de narrativas incide a partir das evidências que as atualizações das práticas culturais de discriminações se dão no jogo entre pessoas-artefatos e as interações das histórias de seus ascendentes a descendentes.

Parte do conflito se formou historicamente na construção de métodos de identificação das populações negras e/ou de matrizes africanas que se compuseram entre (a) questão fisiológica, fenótipo como cor da pele, cabelos etc; (b) a linguagem, isto é, os processos de auto declaração de pertencimento a uma etnia; (c) os processos de formação de cultura a partir da produção de sentidos intergeracional da pessoa em comunidade. No conflito entre culturas, a carta de alforria se caracteriza nos posicionamentos de recursos constituídos na cultura, nos artefatos físicos, simbólicos, convencionalizações.

\section{O fundamento teórico: a família nas gerações e entre gerações}

Caracterizamos a família como o conjunto de pessoas a partir das narrativas de suas experiências significativas e memórias familiares de ações e reverberações do discurso que flui. 
Interpretamos as memórias familiares na rede de significações sociais ${ }^{13}$, ${ }^{14}$, em que discursos de recordações reverberam ${ }^{15}$ formadas por diferentes discursos, tanto concretizados nas histórias familiares, como também em discursos de outros familiares, pessoas que compõem as memórias coletivas, experiências significativas e práticas culturais ${ }^{16}$.

Sendo assim, as narrativas produzem em uma variedade de gêneros do discurso que pressupõe a variedade dos escopos intencionais do participante, em que cada enunciado é um elo na cadeia de outros enunciados ${ }^{17},{ }^{18}$ sobre as transições na constituição familiar no aqui-e-agora, ao contar as histórias de vida intergeracional ou ouvir/ler narrativas sobre sucessos e insucessos de famílias na comunidade. Nesses enunciados estão pessoas integrantes dos conflitos e negociações que, em muitos casos, são excluídos das narrativas de história de vida nas gerações posteriores, mas, que estão na memória familiar ${ }^{19}$. A cada instante na memória pessoal e familiar entre gerações, a constituição das famílias se desdobra em novos arranjos conjugais, a partir da dinâmica de produção de sentidos intergeracional, do materialismo histórico que concretiza a circularidade dos significados sociais e culturais no tempo.

Compõem também a memória familiar intergeracional ${ }^{20}$, não somente os membros presentes em seu cotidiano e os que se foram que se presentificam sendo mediados por instrumentos materiais e lembranças e, também, os que por alguma razão possam estar escondidos ou se constituem em silêncios como muitas vezes os filhos bastardos, e ainda o espaço subjetivo do abandono do pai, mesmo se a informação que os filhos receberam foi do falecimento paterno $^{21}$. Os motivos destes abandonos se personificam em episódios idiossincráticos ${ }^{22}$ que

\footnotetext{
${ }^{13}$ Verón, Eliséo \& Ford, Anibal. Dossier sobre experiencia y discurso. Revista de Estudios Sociales, 108, 39-44, 2006. Disponível em www.periodicos.capes.gov.br. Consultado em 15 de setembro 2017.

${ }^{14}$ Verón, Eliséo. A produção do sentido. São Paulo: Cutrix, 1987.

${ }^{15}$ Silveira, Fabricio José Nascimento. Reverberações do simbólico: ponderações em torno da cultura popular e de suas modulações midiáticas. Revista contemporânea comunicação e cultura, volume 10, número 3, (794-816), 2012. Disponível em www.scielo.br. Consultado em 15 de setembro 2017

${ }^{16}$ Mieto, Gabriela Sousa Melo, Rosa Rivero, Alberto \& Barbato, Silviane. O estudo da produção de significados em interações: metodologias qualitativas. 2016. In: Maria Claudia Santos Lopes de Oliveira; Jane F. Chagas-Ferreira; Gabriela Mieto \& Rossana Beraldo. (Org.). Desenvolvimento Humano: cultura e educação. 1ed.Campinas-SP: Alinea, 2016, v. 1, (89-113).

${ }^{17}$ Bakhtin, Mikhail Mjkhailovitch. Estética da criação verbal. Trad. Pereira, M E. G. P., 2a edição. São Paulo: Martins Fontes, 2003.

${ }^{18}$ Volosinov, Valentin Nikolaevich. Marxismo e filosofia da linguagem. (Pereira, M. E. G., Trad.). 12a edição, 2006. São Paulo: Hucitec.

${ }^{19}$ Larrain, Antonia; \& Hayé, Andrés. The discursive nature of inner speech. Review Theory Psychology volume 22, número 1, (3-22), 2012. Disponível em http://tap.sagepub.com/content/22/1/3.abstract.

${ }^{20}$ Thompson, Paul. A transmissão cultural entre gerações dentro das famílias uma abordagem centrada em histórias de vida. São Paulo: Hucitec-Anpocs, 1993.

${ }^{21}$ Cannell, Fenella. English ancestors: the moral possibilities of popular genealogy. Journal of the Royal Anthropological Institute, v. 17 no 3, (462-480), 2011. Disponível em www.jstor.com. Consultado em 02 fev. 2017.
} 
reverberam em processos saúde-doença na família. Nessa racionalização do humano, o pai se objetifica numa foto, no espaço da certidão de nascimento, e também nas narrativas dos que contam as histórias mediadas por crenças e valores sobre o pai, como a mãe ${ }^{23}$.

Essas crenças e valores intergeracionais nas famílias criam múltiplos horizontes interpretativos do cotidiano e da história, que se relacionam aos diálogos heteroglóticos, pluridiscursivos, nos quais a palavra entre o outro-eu constitui microculturas. Nesses diálogos, palavras e valores provocam quebras e são negociadas, formando as línguas sociais, conjuntos de perspectivas de mundo, em que cada horizonte avaliativo pode se materializar verbalmente ${ }^{24}$.

Ao participar desses diálogos, os signos dos seus antepassados podem ser disponibilizados na fala de alguém, num objeto que se torna pivô na comunicação, na rede de significações que se atualizam na interação ${ }^{25}$. Fazendo uma analogia com o trabalho de Thompson ${ }^{26}$ sobre a transmissão cultural entre gerações nas famílias, podemos afirmar que somos respostas dos discursos dos nossos pais, estes dos nossos avôs, estes dos nossos bisavôs e assim sucessivamente, sem desconsiderar que no tempo presente são distribuídos os interesses de diferentes gerações e pessoas na família. Quando tratamos das respostas dos discursos, referimos à rede de semioses que nos interconectam histórica e culturalmente ${ }^{27}$ aos nossos ancestrais, para além de nossas gerações. E ao identificarmos em nossa geração, pouco percebemos dessa rede de significados, devido aos sentidos de família que percorrem a própria família ${ }^{28}$.

Com esse construto teórico percebemos elementos que não estão no script de significações possíveis da leitura das cartas de alforria. Porque as hipóteses que orientam nosso fazer científico nos levam a comparar o mundo conhecível com o conhecido, pois os

\footnotetext{
${ }^{22}$ Carter, Betty; \& Mcgoldrick, Monica. As mudanças no ciclo de vida familiar: uma estrutura para a terapia familiar. 2a Ed. (Veronese, M. A. V. Trad.) Porto Alegre: Artes Médicas, 2008.

${ }^{23}$ Santos, Julio César. A produção de sentidos intergeracional de homens sobre o planejamento familiar. (Tese) Doutorado. Universidade de Brasília - DF, Instituto de Psicologia, Programa de Pós-Graduação em Processos de Desenvolvimento Humano, 2015.

${ }^{24}$ Faraco, Carlos Alberto, \& Negri, Ligia. O falante: que bicho é esse, afinal? Letras, Curitiba, n. 49, pp. $171-180$. Editora da UFPR, 2010. Disponível em http://dialnet.unirioja.es/servlet/articulo?codigo=2631555.

${ }^{25}$ Volosinov, Valentin Nikolaevich. Marxismo e filosofia da linguagem. (Pereira, M. E. G., Trad.). 12a edição, São Paulo: Hucitec, 2006.

${ }^{26}$ Thompson, Paul. A voz do passado: História oral. Trad. Oliveira, L. L. Rio de Janeiro: Paz e Terra, 1992. Disponível em www.periodicos.capes.gov.br.

27 Bakhurst, David. Reflections on activity theory. Educational Review. Volume 61, número 2, (197-210), 2009. Disponível em www.periodicos.capes.gov.br. acessado em 24/09/2017

${ }^{28}$ Dessen, Maria Auxiliadora. \& Campos-Ramos, Patricia Cristina. Crianças pré-escolares e suas concepções de família. Paidéia, volume 20, número (47) (345-357), 2010. Disponível em www.redalyc.org; consultado em 15 de setembro de 2017.
} 
instrumentos que mediam as relações com o mundo exterior são os mesmos que potencializam e limitam nossas respostas a um mundo definível a partir da construção daquele instrumento ${ }^{29}$.

\section{Algumas discussões das práticas da saúde mental da população negra}

Nos estudos da população negra é possível observar as contribuições aos estudos da saúde mental pelo campo da ancestralidade, dentre os quais se insere o atual artigo a respeito das cartas de alforria como também do conselho de família. $\mathrm{O}$ atual artigo se caracteriza por observar nas cartas de alforria formas de entender-se a si mesmo mediados por significados intergeracionais, nos formatos dos estudos da ancestralidade ${ }^{30}$. Entre as gerações, as dificuldades da pessoa na família são parte de debates no Conselho de Famílias, uma instituição interfamiliar, na qual as pessoas honrosas da família, parentes e amigos próximos se reúnem para aconselhamentos mútuos, na proposta de construção de soluções para as novas situações-problema de algum membro da família. O conselho se reúne em celebrações, festas de família, nascimentos e mortes. Outros campos que constituem formas de se ter saúde mental nos estudos da população negra são os conhecimentos das práticas culturais sobre plantas medicinais, terapias holísticas, celebrações, roda de capoeira, samba de roda, religiões de matrizes africanas e comidas típicas ${ }^{31}$.

Uma das tensões mais frequentes em qualquer sistema de saúde está entre os conhecimentos tradicionais, mais conhecidos como práticas de saúde e as regulações das políticas de saúde. Em muitos países os prestadores de cuidados de saúde com base em abordagens não biomédicas - os praticantes da medicina chinesa, da medicina tradicional africana, ayurvédica também constroem a sua identidade como setor profissional ${ }^{32}$. A partir de novos estudos no Brasil, a política de práticas integrativas e complementares se estabelece e disponibiliza recursos as práticas dos conhecimentos tradicionais no Sistema Único de Saúde, o qual se ampliou com outros procedimentos até mesmo no tratamento da saúde mental com as plantas medicinais, fitoterapia, arteterapia, dança circular, meditação, musicoterapia, terapia comunitária

\footnotetext{
${ }^{29}$ Vygotsky, Lev Semenovitch. Problemas teóricos y metodológicos de la psicología. In: Obras escogidas, tomo I. (J. M. Bravo trad.). Madrid: A Machado Librós S. A. (1-140), 2001.

${ }^{30}$ Santos, Julio César. A produção de sentidos intergeracional de homens sobre o planejamento familiar. (Tese) Doutorado. Universidade de Brasília - DF, Instituto de Psicologia, Programa de Pós-Graduação em Processos de Desenvolvimento Humano, 2015.

${ }^{31}$ Adam, Yussuf. Medicina Tradicional - Medicina dos Hospitais: a escolha dos pacientes. [data?\}, In: Kotnyi, Sophie. Espírito Corpo: materiais para uma difusão activa do filme, 2003.

32 Idem.
} 
integrativa ${ }^{33}$; algumas das práticas estão presentes entre as formas de se obter saúde mental entre os afrodescendentes.

No entanto, no campo da psicologia do mainstream se sobressai as constituições de medidas sobre os graus de saúde mental. Desde a decolonialidade, alguns psicometristas burlaram os testes de inteligência para discriminar a população negra cientificamente na decolonialidade. No projeto decolonial se entrelaçam lugar e pensamento, fronteiras são reinventadas, como também se constroem loci enunciativos de onde são formulados outros conhecimentos a partir da perspectiva de experiências dos sujeitos considerados subalternos ${ }^{34}$. Assim durante algum tempo do século XIX e XX foi possível encontrar narrativas em que a população negra era modulada pelo contexto intersubjetivo presente na sociedade, a desenvolver, em termos psíquicos, o sentimento de inferioridade em relação a outras populações e grupos étnicos. Neste período considerava-se o termo "raça", como identificação da pessoa negra a partir da cor da pele, um dos focos da discriminação racial composta pelo fenótipo.

No estudo de terapias familiares, autores como Carter e McGoldrick ${ }^{35}$ reconhecem que são $^{2}$ as famílias negras as que mais são encaminhadas a serviços clínicos de psicologia. Os autores entendem que a discriminação potencialmente limita os membros da família negra em sua capacidade de funcionar de uma maneira que permita progredirem. A compreensão social da discriminação pode ser aproximar ao significado ofensivo de ser humilhado ou menosprezado as quais despertam formas de funcionamento diferentes, conforme a etnia, no desenvolvimento humano.

É preciso considerar, no entanto, que a realidade brasileira no que tange aos estudos sobre a psicologia, psiquiatria e as constelações familiares, apresenta reduzidas fontes de estudos sobre as especificidades de nossa população negra. Cabe considerar a questão: Porque os psicólogos americanos se interessam tanto por sua população negra e os diferentes grupos étnicos raciais

\footnotetext{
33 MS/Brasil. Portaria número 849 de 27 de março de 2017. Brasília: Diário Oficial da União, 2017. In: www.jusbrasil.com.br; consultado em 15 de setembro/2017.

${ }^{34}$ Bernardino-Costa, Joaze e Grosfoguel, Ramón. Decolonialidade e perspectiva negra. Soc. estado. [online]. volume 31, número 1, (15-24), 2016. In: http://dx.doi.org/10.1590/S0102-69922016000100002. Consultado em 15 de setembro 2017.

${ }^{35}$ Carter, Betty; \& McGoldrick, Monica. As mudanças no ciclo de vida familiar: uma estrutura para a terapia familiar. 2a Ed. (Veronese, M. A. V. Trad.) Porto Alegre: Artes Médicas, 2008.
} 
presentes em sua sociedade e os psicólogos brasileiros não ${ }^{36}$ Quais são os temas nas cartas de alforria que marcam as narrativas da discriminação racial nas ações e atividades atuais?

\section{Método}

O método constitui-se da escolha de 3 homens da mesma família no corte do corpus de narrativas de doze homens, de três gerações, do Quilombo Alto do Morro, da cidade de Santo Antônio de Jesus, Bahia. Foram realizadas quarenta e oito horas de gravações de áudio e vídeo das entrevistas de história de vida e episódica. Outro método foi a pesquisa documental nos cartórios da cidade em busca das cartas de alforria, como também do seu antônimo, a declaração de posse de uma pessoa sobre a outra nas transmissões de bens das famílias entre os anos de 1872 a 1884 entre gerações na mesma cidade. Os documentos da política pública, as cartas de alforria e seu antônimo foram submetidos à análise de conteúdo temática, e as entrevistas à análise dialógica e de pragmática discursiva. Para a identificação dos temas nas entrevistas foi feito análise da informação e análise temática no confronto entre sentidos produzidos nas interações e a interpretação que os entrevistados estão tecendo. No texto, os nomes dos membros da família se transformaram em legendas para manter o sigilo pessoal conforme resolução 466/2012 do Conselho Nacional de Saúde: por exemplo, o avô é P31; o pai é P32 e o filho-neto P33 dos participantes da quarta família. O estudo foi encaminhado ao Conselho de Ética correspondente.

\section{Resultados}

A equipe de pesquisa enfrentou os entraves ditos jurídicos ao acesso às cartas de alforria, um documento que parece de domínio público. Foram necessárias várias idas e vindas à biblioteca pública da cidade, aos cartórios de várias cidades em dois anos seguidos, com assinaturas no Termo de Consentimento Livre e Esclarecido, sem, contudo, termos vistos nenhuma carta de alforria ou declaração de transmissão de bens econômicos. Os responsáveis pela guarda dos documentos nos cartórios privados solicitavam que os estudantes de iniciação científica voltassem em outro momento na próxima semana, pois a pessoa responsável saíra minutos antes da chegada da equipe de pesquisa. Após dois anos, o coordenador do projeto peticionou com pedido

\footnotetext{
${ }^{36}$ Oliveira, Regina Marques de Souza. A formaçao do psicologo nos contextos da diaspora africana. In :Dilemas da raça. Empoderamento e resistência. Oliveira, R. J. e Oliveira, R. M. S. (Orgs.).Sao Paulo : Alameda Casa Editorial, 2017, p.176.
} 
de esclarecimentos aos juízes da cidade. Assim, somente após anos de idas e vindas foi possível iniciar a pesquisa. Os resultados estão compostos a partir da análise de conteúdo temático das cartas de alforria, como também da declaração de posses na avaliação de bens do inventário patrimonial de famílias em 1872 a 1884 no Recôncavo da Bahia. Segue uma carta de alforria, de liberdade de 1884, das mais de 200 registros encontrados pela pesquisa:

\section{Carta de liberdade do escravo Adão}

Digo eu abaixo assinado que sou legítimo dono e possuidor de um escravo de nome Adão, de cor preta, matriculado na cidade de Nazareth com o no 5201 no 1 o de Junho do corrente ano, ao qual concedo sua liberdade, quando prestar-me 26 semanas de seus serviços dentro de um ano, a contar desta data em diante, e quando cumprir a cláusula, Ihe passarei recibo ao pé desta, para gozar de sua inteira liberdade como se do livre ventre nascesse, pois se assim faço, é da minha livre vontade, sem constrangimento algum, e por assim ser mandei passar a presente por Francisco Alves Vieira, na qual assino. Fazenda Cachoeira da Freguesia da Lage, 15 de novembro de 1884, Manoel Vicente de Resende. Nada mais se continha nem declarou em (...).

Com base na análise de conteúdo temático do inventário de bens, como a anterior foi possível estabelecer o mapa de temas:

\section{Temas da declaração de posse na avaliação de bens Inventário patrimonial de famílias em 1872 a 1884 \\ Recôncavo da Bahia}

Velho; garantia de valor; africano

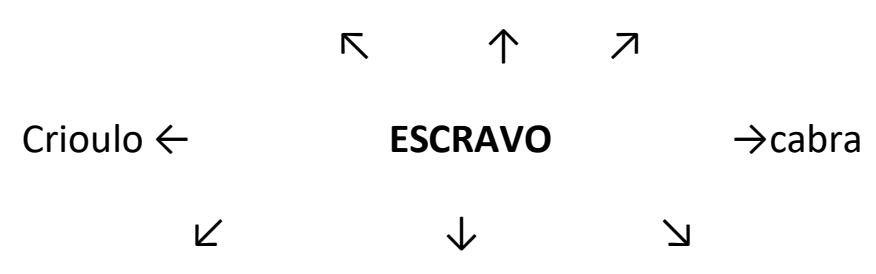

do serviço; Matrícula na coletoria geral; avaliado

$\nvdash \quad y$

Doméstico; da lavoura

Odeere: Revista do Programa de Pós-Graduação em Relações Étnicas e Contemporaneidade - UESB. Ano 2017, Volume 2 número 4, Julho - Dezembro de 2017. 
Para construir o mapa de temas acima tivemos idas e vindas na pesquisa documental dos inventários dos bens de 1872 à 1884. Muitas vezes, as idas e vindas foram para compreendermos a transição gramatical em que ocorreu entre 1872 até os dias de hoje, a linguagem dos significados que posicionam uma pessoa como escravo para o poder judiciário. Entendemos os temas por várias releituras, como a palavra colletoria escrita diferente dos dias atuais coletoria; foram várias as atualizações e retrocessos dos temas para entendermos os significados do escravizado à época e suas reverberações hoje, como também o uso da letra cursiva nos documentos oficiais da justiça. Em uma das declarações de bens os profissionais da justiça separaram três listas entre colunas de escravizados, bens e de dívidas. Foram encontrados à direita do texto o tema "escravo" para significar que o texto descrevia o escravizado de forma numérica dos registros na coletoria, como também as identificações pessoais do mesmo escravizado; ao mesmo tempo no texto da descrição repetia a palavra "escravo" para distinguir a posição contábil do escravizado do resto do grupo. Foi encontrada também uma declaração de posse que mostrava que os escravizados estavam em rebelião na fazenda.

\section{Enunciado da carta de alforria/ de liberdade \\ Inventário patrimonial de famílias em 1872 a 1884 \\ Recôncavo da Bahia}

crioulo; Matrícula na coletoria ; solteiro

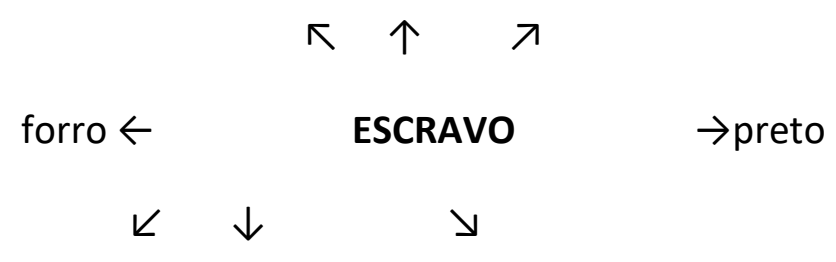

Alforriado; pardo; do serviço da lavoura; avaliado

Entre as duas tematizações, as de cartas de alforria e do inventário patrimonial de famílias negras entre os anos de 1872 à 1884 foram encontrados os temas com significados do 
descendente de africano escravizado para serviço da lavoura entre os dois grupos de documentos, tanto nas cartas de alforria como na declaração de posse. No entanto, foi encontrada apenas duas narrativas de mulheres escravizadas para o serviço doméstico entre as cartas de alforria à época de 1872 a 1884 .

$\mathrm{Na}$ análise de conteúdo temática das cartas de alforria foram encontrados temas de discriminação, racismo e preconceito étnico que reverbera nas atuais narrativas dos participantes, membros do corpus de dados. Foi escolhida a narrativa de P32 por apresentar vários significados que discriminam os negros no interior da comunidade do Quilombo Alto do Morro entre os negros fora do Quilombo, como o "trabalho doméstico" "a minha cor assim". O foco da narrativa enfatiza o impacto da educação, como prática cultural em detrimento aos processos discriminatórios de acesso aos "de minha cor assim". A narrativa de P32 de fala reflexiva, sequencial é quase didática, de idas e vindas em alguns temas, para retomá-los mais consistentes em momentos seguintes sobre a necessidade de P32 juntar dinheiro para a conquista da faculdade:

“(...) 30'41" a 30'47" Que//Hoje tá bom porque...a é... VINTE ANOS ATRÁS UMA PESSOA QUE NEM EU ASSIM, DE MINHA COR ASSIM NUM ia// fazer uma faculdade, quer dizer, no caso fazia, mas era muito DIFÍCIL mesmo, mas hoje qualqué... TRABALHADORA DOMÉSTICA HOJE SE ELA trabalhar e pegando seu dinheiro e juntando, ela consegue FAZER sua faculdade. Porque faz o Enem e faz a FACULDADE e quando pensa que não, vai indo, vai indo, NUM desiste e.... quando passar o período está em argum GRAU melhor. (...) ASSIM UM MÉDICO, UM JORNALISTA ASSIM DA NOSSA COR, mas antigamente não. HOJE JÁ tem, já: Jornalista, e um médico... são um...assim... um vereador, deputado, tudo já tem, tudo da nossa cor assim. Mas antigamente era mais... clarinho..., até chega. //UM HÁBITO//DO NOSSO ASSIM, DO MEU// DO NOSSO PORTE ASSIM, chegá lá era... E a mulher era difícil, hoje que... quer dizer que não. É, melhorou bastante mesmo, é clareou bastante já. ((risos)). 32'05" a 32'12"."

[Enunciado 43 P32 N] [ênfases do autor].

\section{Discussão:}

Cruzamos os dados das pesquisas das cartas de alforria e declarações de posse de uma pessoa sobre a outra, nos inventários patrimoniais que estabelece as marcas de permanência da dinâmica de produção de sentidos intergeracional da discriminação na interação outro-eu. Foi 
focada a discussão de como as práticas educacionais enquanto contexto de política pública, são potenciais para o desenvolvimento humano de qualquer pessoa. Com o contexto, os pesquisadores buscaram entender como as cartas de alforria identificam a população negra, como também reverberações que identificam permanências de significados em ressignificações nas narrativas atuais dos participantes. Esta escolha se caracterizava por se aproximar das discussões atuais da discriminação étnica na decolonialidade ${ }^{37}$. Foi utilizado o tema da educação, que em épocas diferentes as políticas públicas negavam o acesso concreto à população negra. A Lei de 1837/Decreto 1854 - vetava as escolas e aos cursos noturnos o acesso aos escravizados com a seguinte regulamentação ${ }^{38}$ :

"São proibidos de frequentar as escolas públicas; primeiro: todas as pessoas que padecem de moléstias contagiosas. Segundo: os escravos e pretos africanos, ainda que sejam livres ou libertos." (Decreto no 1.331-a, 1854, Câmara dos Deputados, - promulgado - Senado Federal, Legislação Brasileira - 1837)

$\operatorname{Passos}^{39}$ discute aspectos presentes na historiografia da educação da população negra brasileira, com destaques nas proibições impostas pelo Estado aos negros sobre o acesso à escola, no período de transição do trabalho escravo para o trabalho livre no século XIX. A narrativa permite que P32 se posiciona reflexivamente sobre o assunto do acesso à escola para pessoas negras e quase ao final do trecho posiciona diferentemente as pessoas brancas "mais antigamente era mais... Clarinho".

Dispositivos sócio-legislativos surgidos contra o preconceito e discriminação étnica-racial na sociedade brasileira a partir da segunda metade do século $X X$, sinaliza questões intergeracionais importantes, como as reverberações dos significados, a dinâmica de produção de sentidos intergeracionais de escravizados negros alforriados paralisa algumas pessoas, seus ancestrais e descendentes. O self se junta ao próprio self outro-eu, seu pai, seu avô, seu bisavô, seu tataravô que vivenciaram situações de racismo. Compreendemos que P32 se compara às

\footnotetext{
${ }^{37}$ Bernardino-Costa, Joaze e Grosfoguel, Ramón. Decolonialidade e perspectiva negra. Soc. estado. [online]. volume 31, número 1, (15-24), 2016. In: http://dx.doi.org/10.1590/S0102-69922016000100002. Consultado em 15 de setembro 2017.

${ }^{38}$ Câmara dos Deputados. Atividade Legislativa - Decreto no 1.331-a, Rio de Janeiro: Câmara dos Deputados, 1854. Disponível em www.camara.gov.br consultado em 15 de setembro de 2017.

${ }^{39}$ Passos, Joana Célia dos. As desigualdades educacionais, a população negra e a Educação de Jovens e Adultos. Revista EJA em Debate. volume 1, número 1, (137-158), 2012.
} 
empregadas domésticas, que ao juntar um dinheiro, conquistam o acesso à educação de nível superior mediada pelo Exame Nacional de Ensino Médio - Enem.

A ascensão educacional, a qual trata P32, também foi estudada por Oliveira ${ }^{40}$, em sua pesquisa qualitativa, através de narrativas de histórias de vida. Em sua obra, o autor trata da ascensão educacional de uma professora negra, na qual ela contou com a renúncia dos pais e irmãos, na opção estudo versus trabalho, quando ela ainda era jovem. A escolha da educação pelos homens em detrimento do trabalho, nas condições de vida das famílias negras, seria como comprometer a própria sobrevivência. Observou-se a crença social, que identifica o homem negro - sem trabalho - como: moleque, preguiçoso e desonroso ao bom nome da família ${ }^{41}$, ${ }^{42}$. Portanto, aos jovens homens, havia apenas a alternativa de renúncia aos estudos, o que garantia a sobrevivência da família e a promoção educacional da irmã.

Quando P32 renunciou aos estudos, ele havia cumprido uma parte na escola multisseriada na zona rural. A escola multisseriada ia até a 4ạ série, P32 repetiu esta série, mesmo ao ser aprovado pela primeira vez, na esperança que no ano seguinte abrisse o ginásio no Quilombo Alto do Morro. Por essa repetição P32 considera que ele é o único do Quilombo que naquela época conseguiu a 5a série, uma diferença para sua família. Um elevado custo psicológico para buscarem algo tão acessivel aos homens brancos de sua idade, semelhante ao que apontou Gould em seus estudos $^{43}$.

Ao chegar próximo à idade de transição entre a juventude e a adultez, aos 20 anos, P32 ganha um terreno dos pais para iniciar a construção da casa, um símbolo da finalização do tempo da escola e início da vida de casado no contexto do Quilombo. As operações de símbolos convencionalizados na construção da casa, metáfora de constituição da família com filhos pode indicar a participação dos homens na constituição da prole na vigência da primeira relação amorosa. As convencionalizações operavam na direção das exigências sociais da vida familiar: ao parar de estudar, tem que casar; depois dos vinte anos é incomum que negros estudem.

Em nossa pesquisa, encontramos nas narrativas diferenças de anos de estudos entre as três gerações, dificuldades institucionais para o acesso à educação, como também ausência de

\footnotetext{
${ }^{40}$ Oliveira, Iolanda de (Org.). A cor e magistério. Niterói: EDUFF, 2006.

41 Idem

${ }^{42}$ Santos, Julio César. A produção de sentidos intergeracional de homens sobre o planejamento familiar. (Tese) Doutorado. Universidade de Brasília - DF, Instituto de Psicologia, Programa de Pós-Graduação em Processos de Desenvolvimento Humano, 2015.

${ }^{43}$ Gould, Stepen Jay. A falsa medida do homem. Trad. Siqueira, V. S. São Paulo: Martins Fontes, 1991.
} 
sentimento de pertença dos participantes do direito a uma educação pública, digna e de qualidade. Nos resultados da pesquisa os homens no Quilombo Alto do Morro têm quatro anos de estudo, abaixo dos resultados de homens negros e cinquenta por cento a menos dos homens brancos apresentados nos estudos de Oliveira ${ }^{44}$ e Passos ${ }^{45}$. A escolaridade média de um jovem negro de 25 anos de idade gira em torno de 6,1 anos de estudo; um jovem branco na mesma idade tem cerca de 8,4 anos de estudo.

Apesar do nível de escolaridade de brancos e negros ter aumentado de forma contínua ao longo do século XX, a defasagem de 2,3 anos de escolaridade persiste, é a mesma observada entre os pais desses jovens e, de forma geracional, entre os avôs desses jovens. Além disso, o elevado padrão de discriminação étnica, expresso pelo diferencial na escolaridade entre brancos e negros, mantém-se estável entre as gerações. As desigualdades educacionais no Brasil em torno da etnia concretizam uma relação desigual entre salários e nível educacional entre brancos e negros.

Contudo, os estudos de Piketty ${ }^{46}$ sinalizam que as mudanças consideráveis do nível médio de formação não permitiram reduzir as desigualdades da renda do trabalho. $O$ autor discute que o diploma de ensino fundamental de antes é equivalente ao de ensino médio de hoje e, se antes era preciso ser formado numa faculdade para exercício de certa função agora, exige-se um doutorado.

Encontramos um contexto macrocultural em que o participante tece narrativas sobre as ideologias, valores e crenças da diferenciação entre negros e brancos que aponta para o trabalho escravo. Sobre as desigualdades entre negros e não-negros, a produção educacional pode ser observada como uma imagem do exílio da própria terra, a histórica jornada da população negra na educação institucionalizada, um campo atual do estudo da decolonialidade ${ }^{47}$.

Alternativamente, os participantes no quilombo se engajam na construção de ferramentas mediacionais para o uso cotidiano impressos de significados intergeracionais na discussão dinâmica de como cada membro da família vivencia as possibilidades de políticas públicas. Tais políticas se constituem em ferramentas mediacionais para o desenvolvimento humano, enquanto constitutivos de significados da família, presentes nos posicionamentos que

\footnotetext{
${ }^{44}$ Oliveira, Reinaldo José. A cidade e o negro no Brasil. Cidadania e territorio. Alameda :Sao Paulo, 2013.

${ }^{45}$ Passos, Joana Célia dos. As desigualdades educacionais, a população negra e a Educação de Jovens e Adultos. Revista EJA em Debate. Volume 1, número 1, (137-158), 2012.

${ }^{46}$ Pikkety, Thomá. O capital no século XXI. Trad. Bolle, B. M. 1a Ed. Rio de Janeiro: Intrínseca, 2014.

${ }^{47}$ Bernardino-Costa, Joaze e Grosfoguel, Ramón. Decolonialidade e perspectiva negra. Soc. estado. [online]. volume 31, numero 1, (15-24), 2016. In: http://dx.doi.org/10.1590/S0102-69922016000100002. Consultado em 15 de setembro 2017.
} 
mediam/instrumentalizam as ações entre os humanos como tratou Engeström ${ }^{48}$. Estes artefatos têm a possibilidade de capacitar o ser humano de habitar o mundo dos significados, a exemplo da irmã posicionada como a doméstica, "um(a) de nossa cor".

\section{Considerações Finais}

O objetivo do artigo foi entender as narrativas nas cartas de alforria, como dinâmicas de produção de sentidos intergeracionais de pessoas em situações de discriminações étnicas. Nas narrativas das experiências dos participantes em relação às discriminações étnicas foi possível identificar as marcas das maneiras como as pessoas negras se posicionavam e como também eram posicionadas.

No desafio dos estudos da dinâmica de produção de sentidos intergeracional nas cartas de alforria, as pessoas na geração e entre gerações, se conjugam em diferentes formatos narrativos sobre diferentes assuntos cotidianos, objetos, com espaço de recordações, concepções de mundo nas negociações de seus sentidos diários de significados: questionando, comparando, discutindo, concordando ou discordando. Nas narrativas a respeito das cartas de alforria se atualizam sentidos personificados em marcas que se presentificam e indicam os posicionamentos entre as gerações, constroem relatos que demonstram seus significados reprodutores de microcultura dos ancestrais. As pessoas podem construir seu sentido de conhecimento dos ancestrais com base em interações intersubjetivas do participante ${ }^{49}$, mediados pelas cartas de alforria.

As cartas ocorriam em meio às revoltas no contexto de conflitos pela luta por igualdades sociais. Os relatos da sociedade à época até poucos anos atrás mostravam pessoas intolerantes com as tradições culturais africanas ${ }^{50}$ : até a década de 1970, os terreiros de candomblé da região eram obrigados a pedir permissão à polícia para realizarem suas celebrações. A capoeira só foi reconhecida como cultura na década de 1930. E o samba de roda, muitas vezes chamado pelas elites brasileiras de "batuque", só ganhou as ruas e o reconhecimento de bem cultural depois de muitos anos de luta contra o preconceito.

\footnotetext{
${ }^{48}$ Engeström, Y. Activity theory and individual and social transformation. Engeström, Yrjö, et. al. (eds.). Perspectives on activity theory: learning in doing: social, cognitive \& computational perspectives. New York: Cambridge U. P., 2006. Disponível em www.ebooks.cambridge.org.

${ }^{49}$ Dessen, M. A. \& Campos Ramos, P. C. Crianças pré-escolares e suas concepções de família. Paidéia, volume 20, número 47, (345-357), 2010. Disponível em www.redalyc.org

${ }^{50}$ Relatório de Autoavaliação Institucional: Relatório Parcial I do Ciclo Avaliativo 2015-2017 / Comissão Própria de Avaliação - CPA / Universidade Federal do Recôncavo da Bahia - UFRB. Cruz das Almas - BA: UFRB, 2016.
} 
Com o cruzamento dos dados entre as cartas de alforria e as narrativas de P32 o artigo identificou as mudanças no desenvolvimento humano, como também a pressão psíquica da pessoa negra, para chegar em posições sociais que os não-negros chegam sem tantas privações e esforços. Portanto, este é um campo da saúde mental que necessita aprofundamento a partir do estudo de outros pesquisadores de modo interdisciplinar.

Conforme Oliveira, a saúde mental da população humana passa necessariamente pela atrocidade vivida e/ou acometida por outras gerações e estarão a influenciar nos modos de vida e existência das pessoas ${ }^{51}$.

Conclui-se que todos os participantes da pesquisa, a população negra entrevistada, os sobreviventes do processo de escravização do negro africano e os alforriados, querem esquecer os episódios afetos ao tratamento inferiorizado. Buscando isso, mobilizam todos os recursos emocionais, a partir do uso de processos cognitivos possíveis nas formas de transmitir e contar os episódios marcantes de suas histórias de vida às suas crianças, familiares e esposas. Deste modo, as narrativas de pai para filho podem ser transmitidas a partir de histórias de vida em intervalos de sequências. Revelando a negociação intersubjetiva e psicossocial dos processos de construção de si mesmos e de suas identidades.

\section{Referências}

Bakhtin, Mikhail Mjkhailovitch. Estética da criação verbal. Trad. Pereira, M E. G. P., 2ª edição. São Paulo: Martins Fontes, 2003.

Bakhurst, David. Il'enkov On Education. Studies in East European Thought: The Philosophy of Evald Il'enkov volume 57, número (3/4), 2005, (261-275),. Disponível em www.jstor.org. Acesso em 24/09/2017.

Bakhurst, David. Reflections on activity theory. Educational Review. Volume 61, número 2, 2009, (197-210). Disponível em www.periodicos.capes.gov.br. acessado em 24/09/2017

Bernardino-Costa, Joaze e Grosfoguel, Ramón. Decolonialidade e perspectiva negra. Soc. estado. [online]. 2016, vol.31, n.1, pp.15-24. http://dx.doi.org/10.1590/S0102-69922016000100002. Consultado em 15 de setembro 2017.

\footnotetext{
${ }^{51}$ Oliveira, Regina Marques de Souza. Nosso mundo adulto e suas raizes na infância.Saude mental da populaçao negra e indigena. In: Oliveira, R.M.S. Cenarios da saude da populaçao negra no Brasil. Dialogos e pesquisas. Ed. Fino Traço/EDUFRB, Belo Horizonte/Cruz das Almas, 2016, p.36.
} 
Bruner, Jerome Seymour. A. Actos de significado: Más allá de la revolución cognitiva. Madrid: Alianza Editorial, 1991.

Cannell, Fenella. English ancestors: the moral possibilities of popular genealogy. Journal of the Royal Anthropological Institute, v. 17 no 3, (462-480), 2011. Disponível em www.jstor.com. Consultado em 02 fev. 2016.

Carter, Betty; \& McGoldrick, Monica. As mudanças no ciclo de vida familiar: uma estrutura para a terapia familiar. 2a Ed. (Veronese, M. A. V. Trad.) Porto Alegre: Artes Médicas, 2008.

Certeau, Michel de. A invenção do cotidiano: as artes do fazer. Petrópolis: Vozes, 1998.

Comissão Própria de Avaliação. Relatório de autoavaliação institucional do ciclo avaliativo 20152017 da Universidade Federal do Recôncavo da Bahia - UFRB. Cruz das Almas: PROPAAE/UFRB, 2016.

Dessen, Maria Auxiliadora. \& Campos-Ramos, Patricia Cristina. Crianças pré-escolares e suas concepções de família. Paidéia, volume 20, número (47) (345-357), 2010. Disponível em www.redalyc.org

Faraco, Carlos A.Lberto, \& Negri, Ligia. O falante: que bicho é esse, afinal? Letras, Curitiba, n. 49, pp. 171-180. Editora da UFPR, 2010. Disponível em http://dialnet.unirioja.es/servlet/articulo?codigo=2631555.

Fracchia, Joseph. Hora: Social Conflicts and Collective Memories in Piana Degli Albanesi. Past and Present, volume 209, número 1, (181-222), 2010. Disponível em www.periodicos.capes.gov.br.

Fracchia, Joseph, \& Lewontin, Richard Charles. Forum: does culture evolve? The price of metaphor. History and Theory. Volume 44, (14-29), 2005. Disponível em www.periodicos.capes.gov.br

Halbwachs, Maurice. (2006). A memória coletiva. 1a Ed, São Paulo: Editora Centauro.

Larrain, Antonia; \& Hayé, Andrés. The discursive nature of inner speech. Review Theory Psychology volume 22, número 1, (3-22), 2012. Disponível em http://tap.sagepub.com/content/22/1/3.abstract.

Marques, Welisson. Funcionalismo, pragmática e análise do discurso: reflexões analítico-críticas. Revista Odisséia. Volume 3, número 0, (1-19), 2009. Disponível em http://www.periodicos.ufrn.br/odisseia/article/view/2055/1489

Mieto, Gabriela Sousa Melo, Rosa Rivero, Alberto \& Barbato, Silviane. O estudo da produção de significados em interações: metodologias qualitativas. 2016. In: Maria Claudia Santos Lopes de Oliveira; Jane F. Chagas-Ferreira; Gabriela Mieto \& Rossana Beraldo. (Org.). Desenvolvimento Humano: cultura e educação. EduCampinas-SP: Alinea, 2016, volume. 1, (89-113). 
Oliveira, lolanda de (Org.). A cor e magistério. Niterói: EDUFF, 2006.

Oliveira, Regina Marques de Souza. A formação do psicólogo nos contextos da diáspora africana. In: Oliveira, R. J. e Oliveira, R.M.S. (Orgs.). Dilemas da raça. Empoderamento e resistência. Alameda Casa Editorial: São Paulo, 2017.

. Nosso mundo adulto e suas raízes na infância. Saúde mental da população negra e indígena. In: Oliveira, R.M.S. Cenarios da saúde da população negra no Brasil: diálogos e pesquisas. Editora Fino Traço/EDUFRB, Belo Horizonte/Cruz das Almas, 2016.

Oliveira, Reinaldo José. A cidade e o negro no Brasil. Cidadania e Territorio. Alameda Casa Editorial, São Paulo, 2013.

Passos, Joana Célia dos. As desigualdades educacionais, a população negra e a Educação de Jovens e Adultos. Revista EJA em Debate. Volume 1, número 1, (137-158), 2012.

Pikkety, Thomá. O capital no século XXI. Trad. Bolle, B. M. 1a Ed. Rio de Janeiro: Intrínseca, 2014.

Santos, Julio César. A produção de sentidos intergeracional de homens sobre o planejamento familiar. (Tese) Doutorado. Universidade de Brasília - DF, Instituto de Psicologia, Programa de PósGraduação em Processos de Desenvolvimento Humano, 2015. Disponivel em www.unb.br , consultado em 15 de setembro de 2017.

Silveira, Fabricio José Nascimento. Reverberações do simbólico: ponderações em torno da cultura popular e de suas modulações midiáticas. Revista contemporânea comunicação e cultura, volume 10, número 3, (794-816), 2012. Disponível em www.scielo.br, consultado em 15 de setembro de 2017.

Thompson, Paul. A voz do passado: História oral. Trad. Oliveira, L. L. Rio de Janeiro: Paz e Terra, 1992. Disponível em www.periodicos.capes.gov.br. Consultado em 15 de setembro de 2017.

Thompson, Paul. A transmissão cultural entre gerações dentro das famílias uma abordagem centrada em histórias de vida. São Paulo: Hucitec-Anpocs, 1993.

Velho, Ana Paula Machado. A semiótica da cultura: apontamentos para uma metodologia de análise da comunicação. Revista Estudos Comunicativos, volume 10, número 23, (249-257), 2009. Disponível em http://www2.pucpr.br/ Consultado em 15 de setembro de 2017.

Verón, Eliséo \& Ford, Anibal. Dossier sobre experiencia y discurso. Revista de Estudios Sociales, 108, 39-44, 2006. Disponível em www.periodicos.capes.gov.br. Consultado em 15 de setembro de 2017.

Verón, Eliséo. A produção do sentido. São Paulo: Cutrix, 1987.

Volosinov, Valentin Nikolaevich. Marxismo e filosofia da linguagem. (Pereira, M. E. G., Trad.). 12a edição, 2006. São Paulo: Hucitec. 
Vygotsky, Lev Semenovitch. Problemas teóricos y metodológicos de la psicología. In: Obras escogidas, tomo I. (J. M. Bravo trad.). Madrid: A Machado Librós S. A. pp. 1-140, 2001.

Júlio César dos Santos: Doutor em Desenvolvimento Humano e Saúde (UnB), Líder do grupo de pesquisa SAED MCTI CNPq - Metodologias para a vida. Professor da Universidade Federal do Recôncavo da Bahia (UFRB/CCS).

Aline Souza da Conceição: Licenciada em Letras (UNEB/BA, Campus Santo Antonio de Jesus), tem experiência na área de Educação, com ênfase em Ensino-Aprendizagem. Membro do Grupo de Pesquisa SAED - Metodologias para a vida.

Artigo recebido para publicação em: Outubro de 2017.

Artigo aprovado para publicação em: Novembro de 2017. 